\title{
Physiology of Cells in the Central Lobes of the Mormyrid Cerebellum
}

\author{
Victor Z. Han and Curtis C. Bell \\ Neurological Sciences Institute, Oregon Health and Sciences University, Beaverton, Oregon 97006
}

The cerebellum of mormyrid electric fish is unusual for its size and for the regularity of its histology. The circuitry of the mormyrid cerebellum is also different from that of the mammalian cerebellum in that mormyrid Purkinje cell axons terminate locally within the cortex on efferent cells, and the cellular regions of termination for climbing fibers and parallel fibers are well separated. These and other features suggest that the mormyrid cerebellum may be a useful site for addressing some functional issues regarding cerebellar circuitry. We have therefore begun to examine the physiology of the mormyrid cerebellum by recording intracellularly from morphologically identified Purkinje cells, efferent cells, Golgi cells, and stellate cells in in vitro slices. Mormyrid Purkinje cells respond to parallel fiber input with an AMPA-mediated EPSP that shows paired pulse facilitation and to climbing fiber input with a large all-or-none AMPAmediated EPSP that shows paired pulse depression. Recordings from the somas of Purkinje cells show three types of spikes in response to injected current: a small, narrow sodium spike; a large, broad sodium spike; and a large broad calcium spike. Efferent cells, Golgi cells, and stellate cells respond to parallel fiber input with an EPSP or EPSP-IPSP sequence and show only large, narrow spikes in response to intracellular current injection. We conclude that the physiology of the mormyrid cerebellum is similar in many ways to the mammalian cerebellum but is also different in ways that may prove instructive concerning the functional circuitry of the cerebellum.

Key words: cerebellum; Purkinje cell; mormyrid; electric fish; calcium spike; sodium spike

\section{Introduction}

The cerebellum of mormyrid electric fish is well known for its extraordinary size and for the crystalline regularity of its histological structure. The morphology of this unusual cerebellum has been studied extensively (Nieuwenhuys and Nicholson, 1969a,b; Meek and Nieuwenhuys, 1991), but almost nothing is known about its physiology. The size and regularity of the mormyrid cerebellum as well as other morphological features of the mormyrid cerebellum suggest that knowledge of its cellular physiology could contribute to an understanding of cerebellar circuitry in general. The present study was therefore aimed at establishing the functional circuitry of the mormyrid cerebellum by determining the responses of the different cell types of the cerebellum to synaptic inputs and to intracellular current injection.

Two morphological features of the mormyrid cerebellum, besides its unusually regular histology, make the mormyrid cerebellum an attractive site for studying the functional circuitry of the cerebellum. One such feature is the clear spatial separation of climbing fiber and parallel fiber inputs to Purkinje cells. Climbing fibers in mormyrids terminate exclusively on smooth dendrites below the molecular layer, whereas parallel fibers terminate on long spiny branchlets that span the entire molecular layer (Nieuwenhuys and Nicholson, 1969b; Meek and Nieuwenhuys,

\footnotetext{
Received Aug. 26, 2003; revised 0ct. 1, 2003; accepted 0ct. 6, 2003.

This work was supported by National Institute of Neurological Diseases and Stroke Grant NS44961 to V.Z.H. and National Institute of Mental Health Grant MH49792 to C.C.B.

Correspondence should be addressed to Dr. Victor Z. Han, Neurological Sciences Institute, Oregon Health and Sciences University, 505 Northwest 185th Avenue, Beaverton, 0R 97006. E-mail: hanv@ohsu.edu.

Copyright $\odot 2003$ Society for Neuroscience $\quad 0270-6474 / 03 / 2311147-11 \$ 15.00 / 0$
}

1991) (Fig. 1). The spatial separation of climbing fiber and parallel fiber inputs should facilitate an analysis of physiological differences in the postsynaptic membranes that receive these two distinct inputs.

A second morphological feature that makes the mormyrid cerebellum attractive for a study of functional circuitry is one that it shares with the cerebellums of other ray-finned (actinopterygian) fishes. The axons of Purkinje cells in ray-finned fishes do not exit from the cortex but instead terminate locally on nearby efferent neurons (also known as eurydendroid cells) that are equivalent to cerebellar nuclear neurons in mammals (Meek, 1998). The proximity of Purkinje cells and their postsynaptic targets in the mormyrid cerebellum should facilitate the physiological analysis of this important synapse.

The cerebellum of mormyrid fish and other ray-finned fishes has three major divisions: the valvula cerebelli, the corpus cerebelli, and the caudal or vestibulolateral cerebellum (Nieuwenhuys and Nicholson, 1969a; Meek, 1998). The corpus cerebelli and the vestibulolateral lobe are probably homologous to the corpus cerebelli and vestibular cerebellum, respectively, of mammals, but the valvula cerebelli is present only in ray-finned fishes. All of the recordings in the present study were made in the corpus cerebelli.

We made intracellular recordings from cerebellar cells in in vitro slices and identified the recorded cells morphologically by injecting biocytin. We examined the responses of Purkinje cells, efferent cells, stellate cells, and Golgi cells to parallel fiber input and to intracellular current injection. We also examined the responses of Purkinje cells to climbing fiber input. Our results show that most of the basic features of cellular physiology in the mam- 
malian cerebellum are also present in the mormyrid cerebellum. Some distinct features were also observed, however, including an unusually shaped climbing fiber response, three types of spikes in Purkinje cells, and efferent cell activation by parallel fibers.

\section{Materials and Methods}

General. All experiments were performed in in vitro slices from the cerebellum of mormyrid fish of the species Gnathonemus petersii. A total of 65 fish were used for these experiments, ranging in length from 9 to $15 \mathrm{~cm}$. Both transverse and parasagittal slices were used. Intracellular recordings were made using both sharp microelectrodes in an interface chamber and whole-cell patch electrodes in a submerged chamber under visual control. Stimulating electrodes were placed in the granule or ganglionic layer to activate climbing fibers and in the molecular layer to activate parallel fibers.

Slice preparation. The fish were deeply anesthetized with tricaine methane sulfonate at a concentration of $100 \mathrm{mg} / \mathrm{l}$. The skull was opened, and the brain was irrigated with ice-cold artificial CSF (ACSF; for composition, see below). In preparing transverse slices, two vertical cuts were made in the transverse plane, one just rostral to the electrosensory lateral line lobe and one just rostral to the mesencephalon. The central block, containing the corpus cerebelli, was transferred to ice-cold ACSF for 1 min to harden it, and the rostral cut surface was glued to a microtome block. In preparing parasagittal slices, the same two transverse cuts as described above and a parasagittal cut were also made along one side of the brain, lateral to the corpus cerebelli. After hardening in ice-cold ACSF, the parasagittally cut surface was glued to the microtome block. The brain blocks were supported during cutting by a U-shaped wall of gelatin (11\%) that was glued behind the brain blocks on the opposite side from the blade. Agar gel $\left(5 \%\right.$, in liquid form at $\left.\sim 32^{\circ} \mathrm{C}\right)$ was poured between the gelatin wall and the surface of the brain to provide further support. The cutting chamber was filled with ice-cold ACSF during slicing. This ACSF was almost sodium-free, with sucrose replacing the $\mathrm{NaCl}$ to reduce excitotoxic shock caused by the slicing (Aghajanian and Rasmussen, 1989). The composition of this low-sodium ACSF was as follows (in mM): $0 \mathrm{NaCl}, 2.0 \mathrm{KCl}, 1.25 \mathrm{KH}_{2} \mathrm{PO}_{4}, 24 \mathrm{NaHCO}_{3}, 2.6 \mathrm{CaCl}_{2}, 1.6$ $\mathrm{MgSO}_{4} \cdot 7 \mathrm{H}_{2} \mathrm{O}, 20$ glucose, and 213 sucrose.

Two thicknesses of slices were used, $350 \mu \mathrm{m}$ for intracellular recordings with sharp electrodes and $200 \mu \mathrm{m}$ for visualized whole-cell patch recordings. Cut slices were transferred to a holding bath where they were kept submerged at room temperature. The ACSF in the holding bath was a 1:1 mixture of low-sodium and normal ACSF. The composition of the normal ACSF was as follows (in mM): $124 \mathrm{NaCl}, 2.0 \mathrm{KCl}, 1.25 \mathrm{KH}_{2} \mathrm{PO}_{4}$, $24 \mathrm{NaHCO}_{3}, 2.6 \mathrm{CaCl}_{2}, 1.6 \mathrm{MgSO}_{4} \cdot 7 \mathrm{H}_{2} \mathrm{O}$, and 20 glucose. Both low$\mathrm{Na}^{+}$and normal ACSF were bubbled with $95 \% \mathrm{O}_{2}$ and $5 \% \mathrm{CO}_{2}, \mathrm{pH}$ 7.2-7.4, $295 \mathrm{mOsm}$. The slices were kept in the holding bath for $\sim 30-60$ min and then maintained in normal ACSF at room temperature.

Individual slices were transferred to an interface recording chamber for intracellular recording with sharp electrodes and to a submerged recording chamber for whole-cell patch recording. The slices were bathed in a continuous flow of oxygenated normal ACSF.

Recording and stimulation. The corpus cerebelli of the mormyrid is divided into four central lobes, $\mathrm{C} 1-\mathrm{C} 4$, with $\mathrm{C} 1$ being most rostral and C4 being most caudal (Nieuwenhuys and Nicholson, 1969a). The different central lobes and layers could be easily distinguished under a dissecting microscope in both transverse and parasagittal slices. Recordings were made randomly from all four lobes and were primarily focused in the ganglionic layer where Purkinje cells and efferent cells are located. All recordings were made at room temperature $\left(22-24^{\circ} \mathrm{C}\right)$. pClamp 8 software (Axon Instruments, Foster City, CA) was used for recording and analyzing the data.

The micropipettes used for intracellular recordings with sharp electrodes were filled with $2 \mathrm{M}$ potassium methyl sulfate containing $2 \%$ biocytin (Molecular Probes, Eugene, OR; or Sigma, St. Louis, MO). The tips were beveled before use and had resistances of 120-180 $\mathrm{M} \Omega$ after beveling. The micropipettes used for field potential recording had tips of 3-5 $\mu \mathrm{m}$ and were filled with $3 \mathrm{M} \mathrm{NaCl}(3-5 \mathrm{M} \Omega)$.

The electrodes used for whole-cell patch recording had resistances of
4-8 $\mathrm{M} \Omega$ after being filled with an internal solution that contained $0.5 \%$ biocytin. The composition of the internal solution was as follows (in mM): $130 \mathrm{~K}$ gluconate, 5 EGTA, 10 HEPES, $3 \mathrm{KCl}, 2 \mathrm{MgCL}_{2}, 4 \mathrm{Na}_{2}$-ATP, $5 \mathrm{Na}_{2}$-phosphocreatine, and $0.4 \mathrm{Na}_{2}-\mathrm{GTP}, \mathrm{pH} 7.4,280 \pm 10 \mathrm{mOsm}$. In experiments with a cesium-based internal solution, the potassium gluconate was replaced by cesium methane sulfonate of equal osmolarity, with the rest of the ingredients remaining the same. Cells were visualized under infrared Nomarski optics using the $40 \times$ water immersion objective of an upright microscope (Axoskop I; Zeiss, Thornwood, NY). The recordings were performed under both voltage- and current-clamp modes using Axopatch 1D and Multiclamp 700A amplifiers. The holding potential under voltage clamp was $-70 \mathrm{mV}$.

The passive capacitive transients resulting from intracellular current injection were sometimes subtracted out while in voltage-clamp mode to make the active currents stand out more clearly. This was done using the $\mathrm{P} / \mathrm{N}$ subtraction procedure, available as part of the pClamp 8 software. In this procedure, the responses to small voltage steps, which are presumed to be subthreshold for the currents being studied, are summed and then subtracted from the responses to large voltage steps, which are equal to the sum of the small voltage steps. The whole-cell patch recordings were discontinued when the leak current was $>400 \mathrm{pA}$.

After the observations of electrophysiology and pharmacology, biocytin in the recording micropipettes was ejected into the recorded cells by applying tip-positive current pulses $(500 \mathrm{msec}$ on and $500 \mathrm{msec}$ off, $0.5-1.5 \mathrm{nA}$ for $10-15 \mathrm{~min}$ for the sharp electrode and $0.5 \mathrm{nA}$ for $5-10 \mathrm{~min}$ for whole-cell patch recording). Slices were fixed in a mixture containing $4 \%$ paraformaldehyde and $0.5 \%$ glutaraldehyde in $0.1 \mathrm{~m}$ phosphate buffer within 30-60 min after the injection of biocytin. Slices were kept in the same fixative overnight.

We used pairs of tungsten electrodes for stimulation. One member of the pair was placed in the tissue, and the other member was placed in the bath. Stimulus pulses of $0.1 \mathrm{msec}$ in duration and 10-100 $\mu \mathrm{A}$ in amplitude with the electrode in the tissue being negative were delivered through a stimulus isolation unit. The stimulating electrode was placed in the molecular layer to activate parallel fibers and in the granule cell layer near the ganglionic layer to activate climbing fibers.

Pharmacology. The following pharmacological agents were used: the glutamate AMPA receptor antagonist 6-cyano-7-nitroquinoxline-2,3dione (CNQX, $10 \mu \mathrm{M})$, the NMDA receptor antagonist $\mathrm{D}(-)$-2-amino5-phosphonopentanoic acid (AP-5, $35 \mu \mathrm{M})$, the $\mathrm{GABA}_{\mathrm{A}}$ receptor antagonist bicuculline methiodide $(30 \mu \mathrm{M})$, the sodium channel blocker tetrodotoxin (TTX, $1 \mu \mathrm{M}$ ), the calcium channel blocker cadmium chloride $(100 \mu \mathrm{M})$, the potassium channel blocker tetraethylammonium chloride (TEA, up to $10 \mathrm{~mm}$ ), the potassium channel blocker 4-aminopyridine (4-AP, up to $5 \mathrm{~mm}$ ), and the potassium channel blocker barium chloride (2 $\mathrm{mm})$.

The role of sodium channels was investigated in some experiments by replacing sodium chloride in the ACSF with choline chloride of equal osmolarity. Sodium channels were also investigated by adding the sodium channel blocker lidocaine $N$-ethyl bromide (QX-314, $5 \mathrm{~mm}$ ) to the internal solution for whole-cell patch recording. All the chemicals and pharmacological agents were purchased from Sigma.

Histology. The slices of $350 \mu \mathrm{m}$ thickness, in which cells had been recorded with sharp micropipettes, were resectioned after overnight fixation. The slices were embedded in $12 \%$ gelatin that was then hardened by immersion in the same fixative solution for $2 \mathrm{hr}$. Fifty-micrometerthick sections for the DAB procedure were cut on a vibratome. The method for revealing biocytin-filled cells with the DAB method has been described previously (Han et al., 1999). The slices of $200 \mu \mathrm{m}$ thickness, in which cells had been recorded with whole-cell patch electrodes, were prepared for fluorescent visualization without resectioning. The fluorescent method for revealing biocytin-stained cells was as follows: slices were incubated in streptavidin, conjugated Texas Red, or FITC (1:200 in $0.1 \mathrm{M}$ phosphate buffer; Molecular Probes) for $4-6 \mathrm{hr}$ and then mounted in the fluorescent mounting medium Vectashield (Vector Laboratories, Burlingame, CA). Biocytin-filled cells revealed with the DAB method were examined in an ordinary microscope and reconstructed using a camera lucida attachment. Biocytin-filled cells revealed with the fluores- 
A

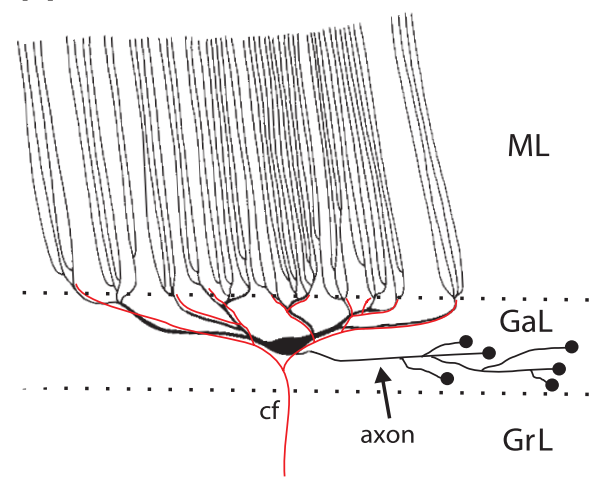

B

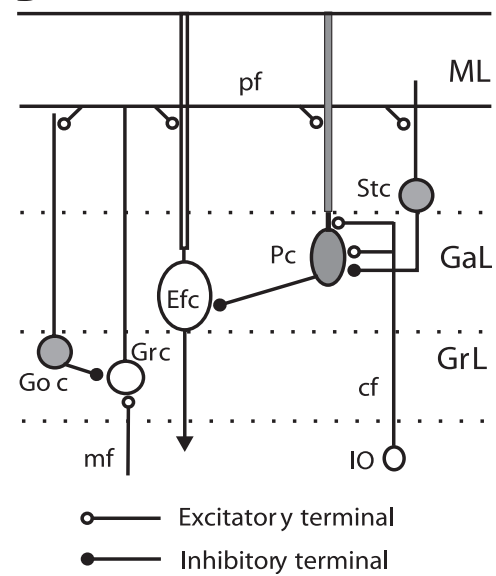

Figure 1. A, Schematic drawing of a Purkinje cell and a single climbing fiber, oriented in the parasagittal plane. The smooth, proximal dendrites of the ganglionic layer give rise to the long, spine-covered dendrites of the molecular layer. The molecular layer dendrites are mostly unbranched and traverse the molecular layer in parallel to each other. The climbing fiber (shown in red) terminates only on the soma and smooth dendrites of the ganglionic layer. B, Diagram of the local circuitry of the central lobes of the mormyrid cerebellum. Some essential features of the mormyrid circuitry are shown. The climbing fiber terminates in the ganglionic layer and does not enter the molecular layer. The Purkinje cell terminates locally on the efferent cell. Parallel fibers excite the molecular layer dendrites of efferent cells, as well as the dendrites of Purkinje cells, Golgi cells, and stellate cells. Inhibitory neurons are shown in gray. cf, Climbing fiber; Efc, efferent cell; GaL, ganglionic layer; Goc, Golgi cell; Grc, granule cell; GrL, granule layer; I0, inferior olive; mf, mossy fiber; ML, molecular layer; Pc, Purkinje cell; pf, parallel fiber; Stc, stellate cell.

cent method were examined in a microscope equipped with epifluorescence and in a confocal microscope.

Our morphological identification of recorded and stained cells in the mormyrid cerebellum was based on the descriptions of Golgi-stained material by Nieuwenhuys and Nicholson (1969) and Meek and Nieuwenhuys (1991). Our morphological findings will be described in a future publication (V. Z. Han, H. R. Campbell, and C. C. Bell, unpublished results). Figure $1 A$ shows a schematic drawing of a Purkinje cell in the parasagittal plane, together with a climbing fiber that terminates on the smooth dendrites of the ganglionic layer. Figure $1 B$ shows a simplified diagram of the cerebellar local circuitry in the central lobes.

\section{Results}

\section{Anatomical overview}

The corpus cerebelli in mormyrids is divided into four lobes, C1-C4 (Nieuwenhuys and Nicholson, 1969a). All four lobes have a similar histological structure consisting of three layers: molecular, ganglionic, and granule. The molecular layer contains parallel fibers, Purkinje cell dendrites, efferent cell dendrites, and stellate cells. The parallel fibers course in the transverse plane, intersecting the sagittally oriented dendrites of Purkinje and efferent cells. The ganglionic layer is beneath the molecular layer. This layer corresponds to the Purkinje cell layer in mammals but is referred to as the "ganglionic" layer in mormyrids because it contains the cell bodies of both efferent cells and Purkinje cells. The granule layer, beneath the ganglionic layer, contains the granule cells, mossy fiber terminals, and Golgi cells. The Golgi cells are distributed throughout the granule layer (Nieuwenhuys and Nicholson, 1969b; Meek and Nieuwenhuys, 1991).

Purkinje cells in the mormyrid cerebellum have short axons that terminate locally on nearby efferent neurons. The axons of efferent neurons convey information out of the cerebellar cortex to other parts of the brain. Parallel fibers of the molecular layer synapse on the dendrites of efferent cells, Purkinje cells, stellate cells, and Golgi cells (Fig. 1B).

\section{Field potential responses to parallel}

\section{fiber stimulation}

We measured conduction velocity in the parallel fibers of the mormyrid cerebellum by recording field potential responses to parallel fiber stimulation in cerebellar slices cut in the transverse plane. The field potential responses consist of three components, an initial, large, brief triphasic wave followed by two smaller, longerlasting negative waves (Fig. $2 \mathrm{~A}$ ). The first component follows stimulus frequencies as high as $500 \mathrm{~Hz}$, indicating that it is attributable to the presynaptic activity in parallel fibers. Conduction velocity was determined by measuring the delay of the negative peak of this first component as a function of distance between the stimulating and recording electrodes (Fig. $2 B$ ). The conduction velocity of parallel fibers was $\sim 0.1 \mathrm{~m} / \mathrm{sec}$ (mean $\pm \mathrm{SE}, 0.11 \pm 0.02$ $\mathrm{m} / \mathrm{sec} ; n=6$ ), a value that is comparable with that found in the mammalian cerebellum (Eccles et al., 1967).

The second and third components of the response to parallel fiber stimulation, the two negative waves, do not follow stimulus frequencies of $>50 \mathrm{~Hz}$, suggesting that they are attributable to activation of postsynaptic elements by the parallel fiber volley. The second component was shorter in duration than the third component and showed paired pulse depression, in contrast to the paired pulse facilitation shown by the third component. EPSPs and EPSCs evoked by parallel fiber stimulation in Purkinje cells and efferent cells consistently show paired pulse facilitation (see below). We therefore assume that the third component of the field potential response is a reflection of the synaptic response in molecular layer dendrites. The origin of the second component is not clear, but we hypothesize that it is attributable to a postsynaptic broad spike in Purkinje cells that can be evoked at a short latency by EPSPs and by intracellular current injection (see below). The paired pulse depression of the second component of the field potential response is explained by refractoriness of this broad spike after its activation.

\section{Purkinje cells}

Most of our recordings were taken from Purkinje cells in this study. This was partly because Purkinje cells are readily recorded and partly because of the central importance of these cells for cerebellar function. We recorded a total of 178 Purkinje cells, 69 of them with sharp electrodes and 109 of them with whole-cell patch electrodes. The membrane potentials for the cells recorded under current clamp were between -61 and $-74 \mathrm{mV}(n=32)$ for the sharp electrode recordings and between -60 and $-77 \mathrm{mV}$ $(n=25)$ for the whole-cell patch recordings. Results with the two types of recordings were quite similar in current-clamp recording. All voltage-clamp recordings were obtained with the wholecell patch technique. Most of our recordings were probably taken from the somas of Purkinje cells. Our sharp electrode penetrations were aimed at the ganglionic layer where the Purkinje cell somas are located, and our whole-cell patch electrodes were applied directly to the soma under visual control. 

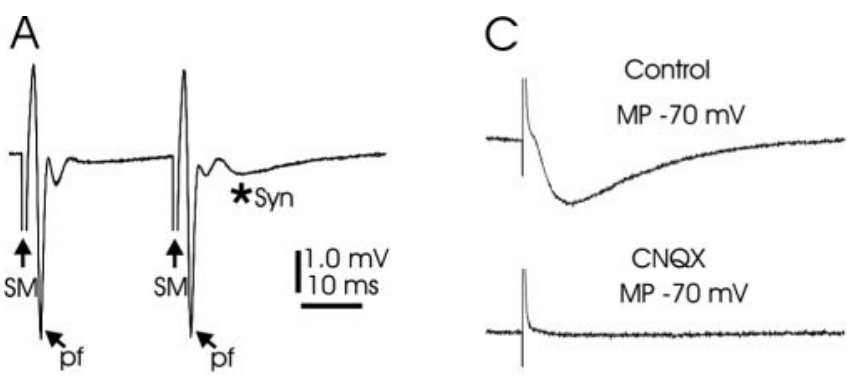

B
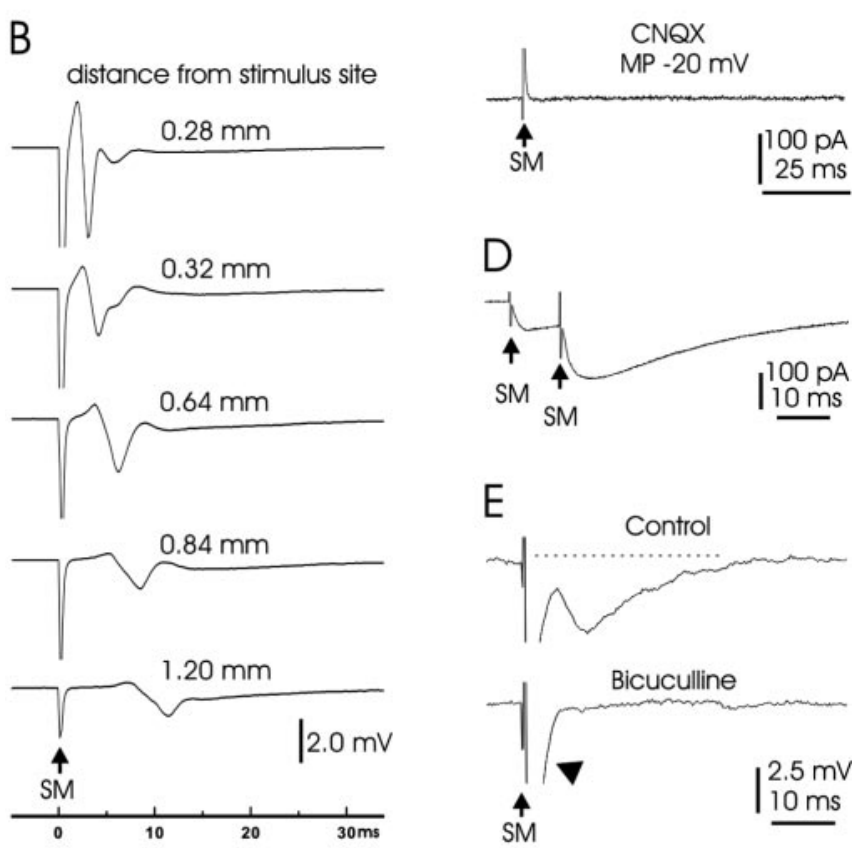

E
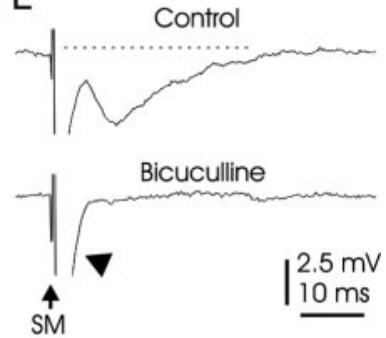

Figure 2. Responses to molecular layer stimulation (SM). A, Field potential responses to a pair of closely spaced molecular layer stimuli. The responses have three components: an initial parallel fiber volley (pf), a brief second component that may reflect a broad spike in the Purkinje cells, and a third component that probably reflects the synaptic response of molecular layer dendrites to parallel fiber activation (syn labeled with an asterisk). $B$, Field potential responses to a molecular layer stimulus recorded at different distances from the stimulating electrode along the parallel fiber beam. The responses were recorded in a transversely cut slice. C, Effects of glutamate receptor antagonist CNQX on a parallel fiber-evoked EPSC in a Purkinje cell. Recordings were obtained under voltage clamp. Note that the response completely disappears after application of the AMPA receptor antagonist CNQX (10 $\mu \mathrm{m})$. The absence of a synaptic response under CNQX at the depolarized potential of $-20 \mathrm{mV}$ (bottom trace) indicates that glutamate receptors of the NMDA type were not activated by the parallel fiber stimulus. $D$, Paired pulse facilitation of the synaptic response of a Purkinje cell to parallel fiber stimulation. Recordings were made under current clamp. Note the larger response to the second of two stimuli separated by $10 \mathrm{msec}$. E, Effect of bicuculline on an IPSP evoked in a Purkinje cell by molecular layer stimulus. Recordings were made under current clamp. Bicuculline (30 $\mu \mathrm{m})$ blocks the IPSP (bottom trace). The initial, downward deflection (arrowhead) is a truncated stimulus artifact.

\section{Responses to parallel fiber stimulation}

The ionotropic synaptic potentials evoked by parallel fiber stimulation in mammalian Purkinje cells are mediated entirely by glutamate receptors of the AMPA type and do not include any NMDA receptor component (Konnerth et al., 1990). The same is true of parallel fiber-evoked synaptic potentials in mormyrid Purkinje cells. The EPSCs or EPSPs evoked by parallel fiber stimulation in mormyrid Purkinje cells were not affected by the NMDA receptor antagonist AP-5 and were either completely blocked by the AMPA antagonist CNQX (14 of 20 cells) or reduced to near 0 ( 6 of 20 cells). No additional synaptic current was observed under CNQX in cells recorded under voltage clamp when the membrane potential was held at $-20 \mathrm{mV}$ (five of five cells) (Fig. 2C). These results indicate the absence of NMDA receptor-mediated transmission because the magnesium block of NMDA receptors would be removed at this potential. The EPSPs and EPSCs evoked by parallel fiber stimulation showed clear paired pulse facilitation when pairs of stimuli were delivered between 10 and $100 \mathrm{msec}(n=30)$, as occurs also in mammals (Eccles et al., 1967; Konnerth et al., 1990) (Fig. 2D).

Parallel fiber stimulation evoked an EPSP without any apparent associated IPSP in most Purkinje cells. IPSPs were evoked by parallel fiber stimulation in some Purkinje cells recorded with sharp electrodes, however. The more frequent observation of IPSPs when recording with sharp electrodes could be attributable to the presence of a chloride ion in the patch pipettes and the absence of this ion in the sharp electrodes. The IPSPs recorded with sharp electrodes were blocked by bicuculline $(n=5)$, indicating that they are mediated by $\mathrm{GABA}_{\mathrm{A}}$ receptors (Fig. $2 E$ ). The GABAergic cells responsible for the IPSPs could be either stellate cells or other Purkinje cells, both of which are activated by parallel fiber stimulation and both of which synapse with Purkinje cells (Meek and Nieuwenhuys, 1991). We did not attempt to determine which of these two cells was responsible for the IPSPs.

\section{Responses to climbing fiber stimulation}

Climbing fiber responses were evoked by stimulation in the ganglionic or granule layer near the recorded Purkinje cell. The responses consisted of large all-or-none EPSPs of 40-50 mV (Fig $3 A$ ). The responses had two distinct phases, a large initial phase lasting $\sim 10 \mathrm{msec}$ followed by a second phase that consisted of a slow return to baseline and lasted $\sim 100 \mathrm{msec}$ (Fig. 3A). Large, broad spikes were sometimes evoked during the initial phase (Fig. $3 A$, second trace). Small, narrow spikes often occurred at the peak of the EPSP, and additional small, narrow spikes were sometimes evoked during the declining second phase (Fig. $3 A$ ). The large all-or-none EPSCs recorded under voltage clamp did not show the two phases (Fig. 3B). Only a single large EPSP was evoked in any one Purkinje cell, indicating that Purkinje cells in the corpus cerebelli of mormyrid fish receive only a single climbing fiber, as in mammals.

The synaptic response to climbing fiber stimulation was similar to mammalian climbing fiber responses in showing a marked paired pulse depression $(n=15)$ (Fig. $3 B$ ) and in being mediated exclusively by AMPA receptors (Konnerth et al., 1990; Hashimoto and Kano, 1998). The AMPA receptor antagonist CNQX either completely abolished the EPSCs (six of seven cells) or reduced them to near 0 (one of seven cells). Mediation by glutamate receptors of the AMPA type was shown by the lack of effect of AP-5 (Fig. 3D) and the absence of any response under CNQX even at the depolarized membrane potential of $-20 \mathrm{mV}$, at which the magnesium block on NMDA receptors would be removed $(n=4)$ (Fig. $3 E)$.

The waveform of the climbing fiber response, consisting of a brief initial phase followed by a long declining phase, was quite different from the waveform observed in the mammalian cerebellum (Eccles et al., 1967; Schmolesky et al., 2003). Climbing fibers in mormyrids terminate exclusively on smooth dendrites of Purkinje cells in the ganglionic layer and do not extend up into the molecular layer as they do in mammals. The many long, spine-covered molecular layer dendrites of Purkinje cells in mormyrids provide a large membrane surface, the capacitance of which would be charged by the strong synaptic current injected into the smooth dendrites by the climbing fiber response. We hypothesize that the long, slow decline of the potential in the 
A

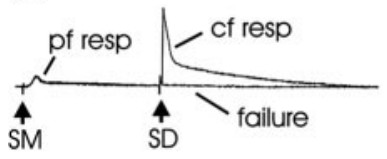

B

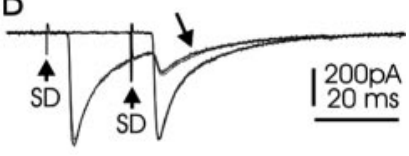

C

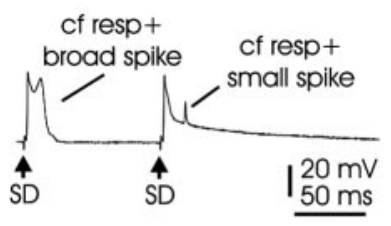

D
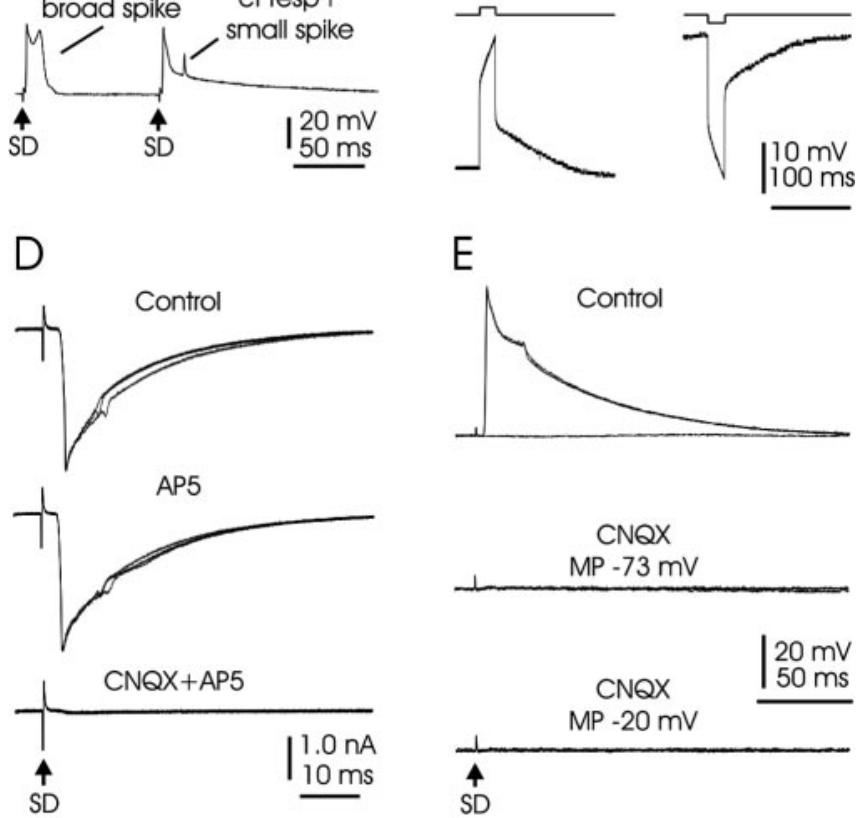

E

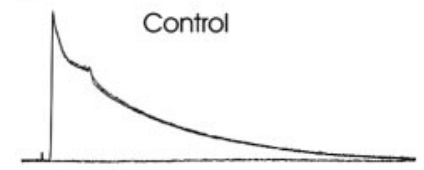

CNQX

$\mathrm{MP}-73 \mathrm{mV}$

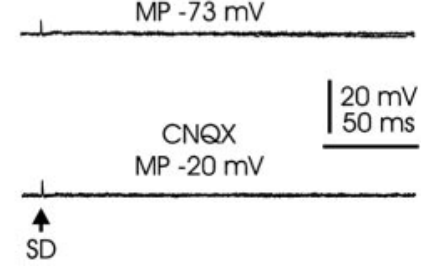

A
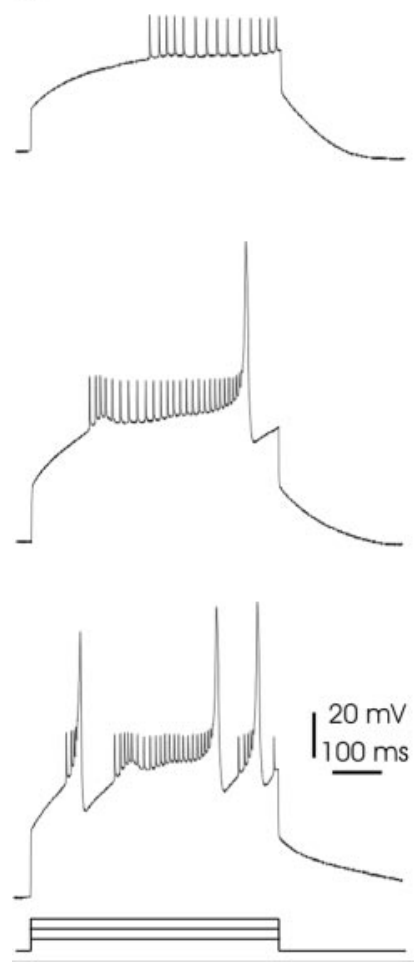

Figure 3. Climbing fiber activation of Purkinje cells. $A$, Responses to molecular layer stimulation (SM) and deep layer stimulation (SD). Recordings were obtained under current clamp. The top trace shows two superimposed sweeps. An initial molecular layer stimulus evokes an EPSP on both sweeps. A subsequent deep layer stimulus is at threshold for a climbing fiber response, evoking a climbing fiber response on one sweep but not on the other. A small, narrow spike is present at the peak of the climbing fiber-evoked EPSP. Note that the large initial phase of the climbing fiber response is followed by a slow, ramp-like return to the baseline. The bottom trace is taken from the same Purkinje cell and shows a single sweep with two deep layer stimuli. Each stimulus evokes a climbing fiber synaptic response. The climbing fiber synaptic response to the first stimulus evokes a broad spike. The synaptic response to the second stimulus does not evoke a broad spike but does evoke an additional small, narrow spike during the second phase of the response. B, Paired pulse depression of the climbing fiber-evoked EPSC. Four superimposed sweeps were recorded under voltage clamp. Pairs of stimuli separated by 20 msec were delivered to the deep layer. Stimuli were near threshold for a climbing fiber EPSC. The EPSC to the second stimulus (downward arrow) was much reduced when the first stimulus evoked an EPSC. The EPSC was of full size when the first stimulus did not evoke a response. C, Response to injection of a brief current pulse into the soma mimics the second phase of the climbing fiber response. Recordings were made under current clamp. Brief current pulses of 50 pA, both depolarizing (left traces) and hyperpolarizing (middle traces), evoke a long-lasting, ramp-like potential with a time course similar to that of the second phase of the climbing fiber response. $D$, The climbing fiber EPSC is mediated by glutamate receptors of the AMPA type. Recordings were made under voltage clamp. The climbing fiber EPSC is not affected by the addition of the NMDA receptor antagonist AP- $5(35 \mu \mathrm{M})$ to the bath but is nearly completely eliminated by the addition of the AMPA receptor antagonist CNQX (10 $\mu \mathrm{M})$. E, The climbing fiber EPSC is not mediated by glutamate receptors of the NMDA type. Recordings were made under current clamp. The all-or-none climbing fiber-evoked EPSP (top traces) is blocked by the AMPA receptor antagonist CNQX (10 $\mu \mathrm{m}$ ) at membrane potentials of both $-73 \mathrm{mV}$ (middle traces) and $-20 \mathrm{mV}$ (bottom traces). The absence of any response under CNQX at $-20 \mathrm{mV}$, a potential at which the NMDA receptors should be open, indicates that these receptors are not present.

climbing fiber response recorded under current clamp reflects the slow passive decay of the charge from the molecular layer dendrites after the injection of current by the climbing fiber. Partial support for this hypothesis was obtained by injecting brief subthreshold pulses of depolarizing and hyperpolarizing current
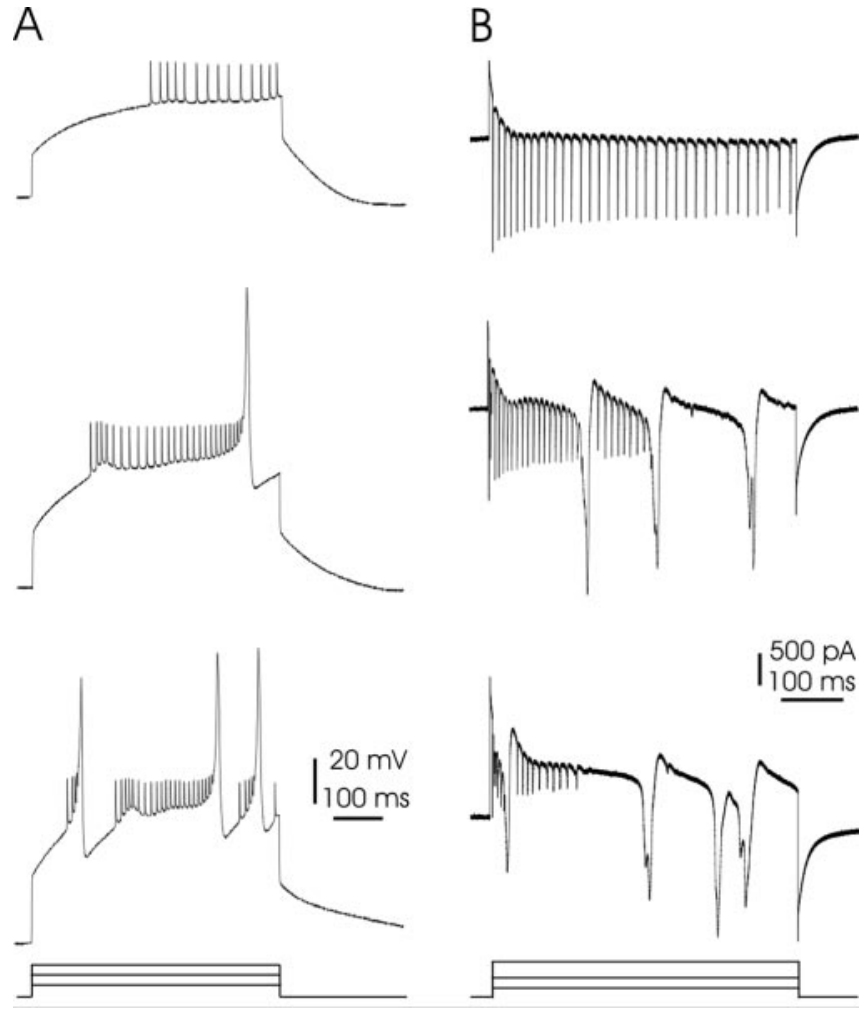

Figure 4. Responses of Purkinje cells to intracellular injection of depolarizing currents and depolarizing voltage steps. A, Responses of a Purkinje cell, recorded under current clamp, to injection of current at three different intensities: top trace, $200 \mathrm{pA}$; middle trace, $400 \mathrm{pA}$; bottom trace, $600 \mathrm{pA}$. B, Responses of another Purkinje cell, recorded under voltage clamp, to voltage steps of three different amplitudes. The cell was depolarized from a holding potential of -70 to -55 (top trace), -40 (middle trace), and -20 (bottom trace) $\mathrm{mV}$.

into the recorded cell and observing the same slow decline in potential that was observed after the initial phase of the climbing fiber response (Fig. 3C).

Three different types of spikes in Purkinje cells

Studies of Purkinje cells in mammals (Llinas and Sugimori, 1980b) and in some other vertebrates (Hounsgaard and Midtgaard, 1988), have generally identified just two types of spikes, a narrow sodium spike and a broad calcium spike. The narrow sodium spike is generated in the soma and axon, whereas the broad calcium spike is generated in the dendrites. In contrast, Purkinje cells of the mormyrid corpus cerebelli have three types of spikes, as observed in recordings from the soma: a small, narrow sodium spike; a large, broad sodium spike; and a large, broad calcium spike.

The three types of spikes are evoked by intracellular current pulses in current-clamp recording and by voltage steps in voltage-clamp recording. We usually examined the three types of spikes in the voltage-clamp mode because control of the resting potential in this mode yielded somewhat more reproducible results. The spikes in the voltage-clamp mode clearly reflect voltage-gated channels at some distance from the electrode, possibly in the dendrites or axons, that are not under voltage control.

In current clamp, the lowest intensity current pulses evoked only small, narrow spikes of $10-15 \mathrm{mV}$ in amplitude and $1 \mathrm{msec}$ in duration (Fig. $4 A$, top trace). Large, narrow spikes of $\geq 50 \mathrm{mV}$ are commonly observed in recordings from the somas of mammalian Purkinje cells (Eccles et al., 1967; Llinas and Sugimori, 1980a). We never observed such large, narrow spikes in any of 
our recordings from mormyrid Purkinje cells, although we consistently saw such spikes in our recordings from other types of cerebellar cells (see below). The consistently small size of these spikes and the fact that most of our recordings were from the soma suggest that the small, narrow spikes are generated away from the soma, and our hypothesis is that they are axon spikes that do not invade the soma.

Additional types of spikes appeared as the intensity of the injected current was increased. These spikes were large and broad, $50-70 \mathrm{mV}$ in amplitude and $8-20 \mathrm{msec}$ in duration. The broad spikes first appeared at a long delay after the start of current injection (Fig. 4A, middle trace) as current intensity was increased above the threshold of the small, narrow spikes. As current intensity was further increased, an early broad spike appeared in addition to the later broad spikes (Fig. $4 A$, bottom trace).

The same types of spikes were observed in voltage-clamp recordings (Fig. $4 B$ ). Small voltage steps yielded only narrow spikes that were $1 \mathrm{msec}$ in duration and $1-2 \mathrm{nA}$ in amplitude. Larger voltage steps yielded large, broad spikes that were $20 \mathrm{msec}$ in duration and 2-4 nA in amplitude. The amplitudes of both narrow and broad spikes, as recorded in voltage clamp, were larger for small depolarizations than for big depolarizations, presumably because of partial inactivation and a lowering of the driving force (Fig. $4 \mathrm{~B}$ ). A gap was always present between the first broad spike and later broad spikes when the first broad spike was evoked at a short latency by the larger current injections (Fig. 4A, $B$, bottom sweeps). All of the cells with small, broad spikes that were morphologically identified were Purkinje cells $(n=133)$. The other cell types had only large, narrow spikes (see below).

Pharmacological methods were used to show that the small, narrow spikes are sodium spikes and that the broad spikes are of two distinct types, an initial broad sodium spike and a later broad calcium spike. Bath application of the sodium channel blocker TTX (1 $\mu \mathrm{M})$ eliminated both the small, narrow spikes and the initial broad spike but left the later broad spike unaffected (Fig. $5 A$, middle trace). Subsequent addition of the calcium channel blocker cadmium (100 $\mu \mathrm{M})$ eliminated the late broad spikes, leaving only a small "hump" at the beginning of the current trace (Fig. $5 A$, bottom trace). This sequence of events was observed in 28 Purkinje cells. When the calcium channel blocker cadmium was given first, the late broad spikes disappeared, but the small, narrow spikes and the initial broad spike remained (Fig. $5 B$, middle trace). Subsequent addition of TTX eliminated both the small, narrow spikes and the initial broad spike, leaving the same small hump at the beginning of the current trace (Fig. $5 B$, bottom trace). This sequence of events was observed in 32 cells. The results strongly suggest that the small, narrow spikes and the initial broad spikes are sodium spikes and that the later broad spikes are calcium spikes.

The finding that the initial broad spike is a sodium spike is surprising, given the previously obtained results in mammalian (Llinas and Sugimori, 1980a,b) and reptilian (Hounsgaard and Midtgaard, 1988) Purkinje cells, indicating that the broad spikes are all calcium spikes. Further evidence that the initial broad spike is a sodium spike was therefore sought by substituting choline for sodium in the bathing medium and by injecting the sodium channel blocker QX-314 into the Purkinje cells.

Substitution of choline for sodium should reduce or eliminate the sodium current because choline is too large to pass through sodium channels. The late broad spikes were first blocked by cadmium in these experiments, leaving only the initial broad spike and the small, narrow spikes (Fig. $6 B$ ). The tissue was then
A

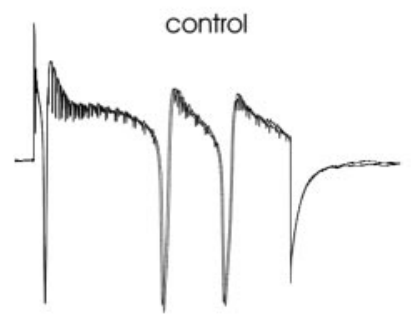

B
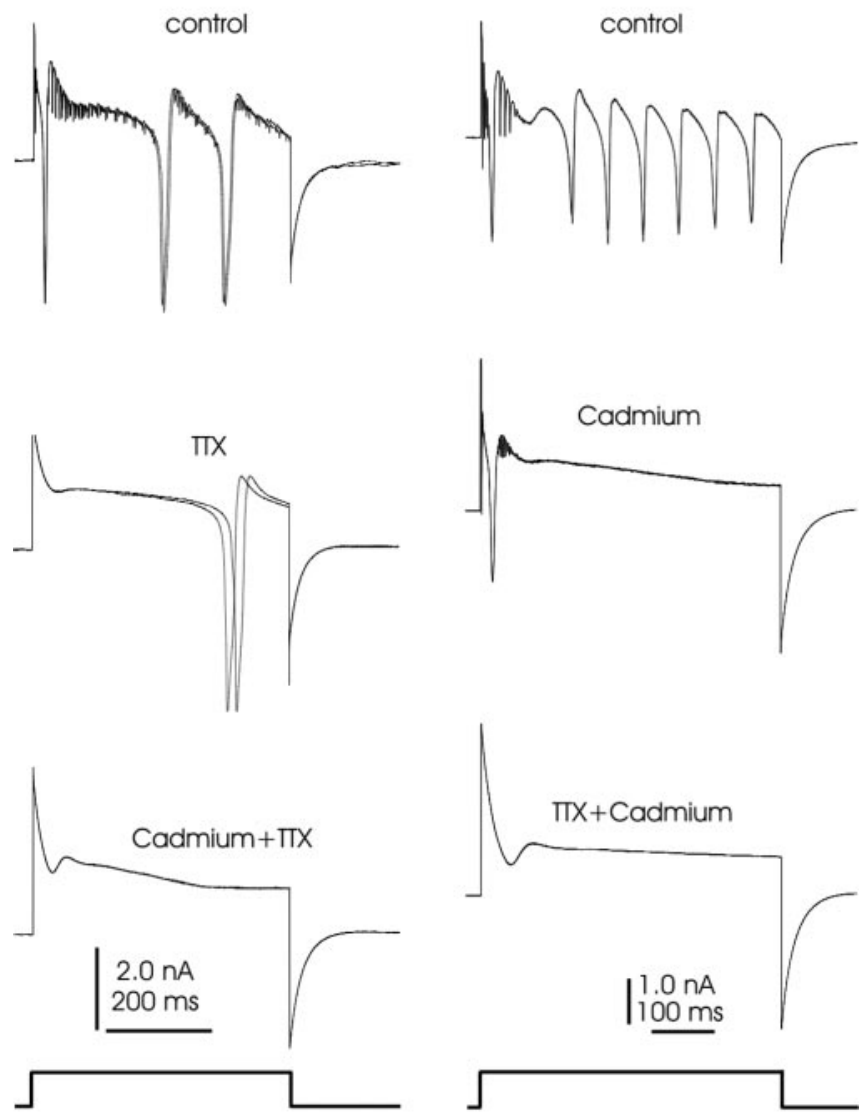

Figure 5. Effects of the sodium channel antagonist TTX and the calcium channel antagonist cadmium on the three different spike types in mormyrid Purkinje cells. All recordings were obtained under voltage clamp. In each recording, the cell was depolarized by a step from the holding potential of $-70 \mathrm{mV}$ to a potential of $-25 \mathrm{mV}$. A, Effects of giving TTX first followed by cadmium. TTX (1 $\mu \mathrm{m})$ makes the initial broad spike and the small, narrow spikes disappear (middle traces). The late broad spike disappears with the further addition of cadmium (bottom traces; $100 \mu \mathrm{m}$ ). A small response to the voltage step (hump) is still present. $B$, Effects of giving cadmium first followed by TTX. Cadmium (100 $\mu \mathrm{m}$ ) makes the late broad spikes disappear (middle traces). The initial broad spike and the small, narrow spike disappear with the further addition of TTX (1 $\mu \mathrm{M})$. A small response to the voltage step (hump) is still present.

superfused with ACSF in which the sodium chloride was replaced with choline chloride. This replacement caused a marked reduction in the small, narrow spikes as well as a reduction, broadening, and delaying of the initial broad spike $(n=5)$ (Fig. $6 C)$. The two returned to their previous size and shape when the slice was superfused with normal ACSF (results not shown). The results provide a further indication that the small, narrow spikes and initial broad spikes are sodium spikes. Both the narrow spikes and the initial broad spike were reduced but not eliminated when sodium chloride was replaced with choline chloride. The continued presence of these spikes under such conditions was probably attributable to the $24 \mathrm{~mm} \mathrm{NaHCO}_{3}$ in the ACSF and to residual sodium in the tissue. Both types of spikes were completely eliminated when TTX was added to the bath (Fig. 6D). The same effects of choline substitution were observed in five Purkinje cells.

The sodium channel blocker QX-314 was included in the patch pipettes in nine Purkinje cells. No narrow spikes and no initial broad spikes were recorded in five of these cells, only late broad spikes. Presumably, the QX-314 diffused into these cells immediately after the membrane was broken and before the ef- 


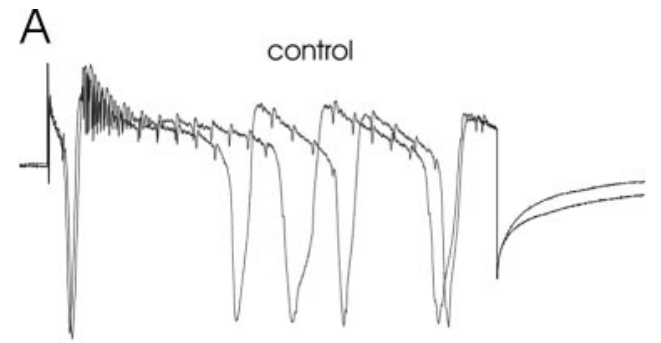

B
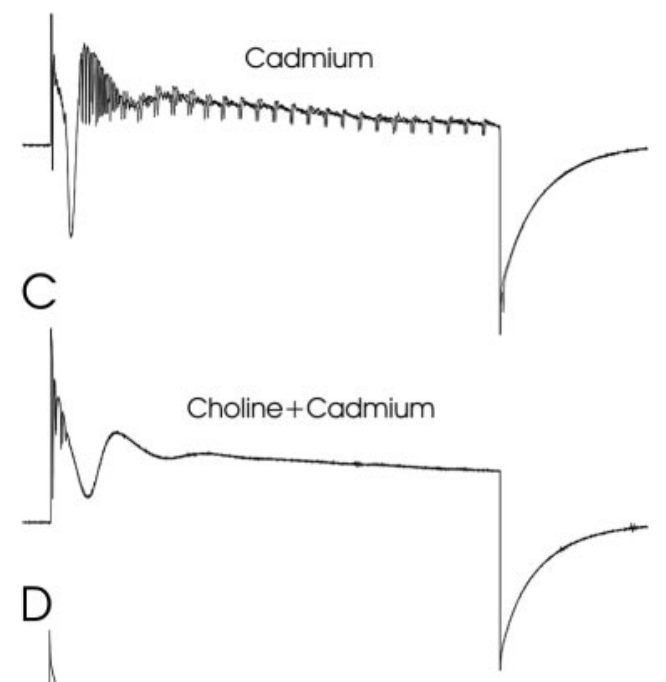

IX+Choline+Cadmium

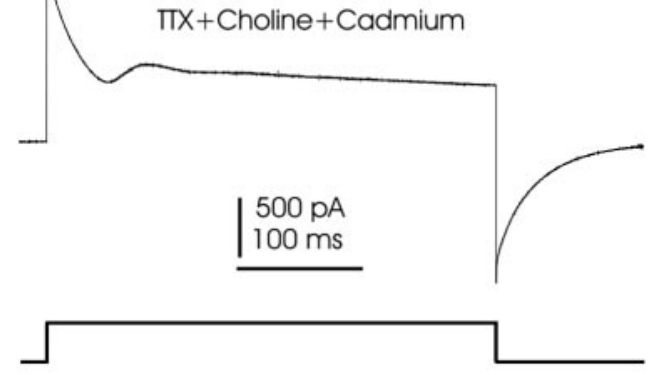

Figure 6. Effects of reduced extracellular sodium on Purkinje cell spikes. All recordings were obtained under voltage clamp. Responses were obtained by voltage steps from a holding potential of -70 to $-25 \mathrm{mV}$. A, Predrug control showing three types of spikes. B, Addition of the calcium channel blocker cadmium (100 $\mu \mathrm{m})$ removes late broad spikes. C, Replacement of sodium chloride with choline chloride in the ACSF reduces the amplitudes of the small, narrow spikes and the initial broad spike. D, Addition of the sodium channel blocker TTX $(1 \mu \mathrm{M})$ removes small, narrow spikes and the initial broad spike, leaving a small response to the voltage step (hump).

fects of current injection could be tested. The narrow spikes and initial broad spikes disappeared within a few minutes in the other four cells tested with QX314.

The calcium basis of the late broad spike was also tested further. The small, narrow spike and the initial broad spike were first eliminated with TTX and replacement of normal ACSF with ACSF in which the choline chloride was substituted for sodium chloride (Fig. $7 B$ ). The late broad spike was still present under these conditions, indicating that it is not mediated by the sodium current (Fig. 7B). (The increase in duration of the late broad spike shown in Figure $7 B$ is probably caused by the partial blockade of potassium channels attributable to cesium in the recording electrode.) The calcium origins of the remaining spikes were then tested by replacing calcium chloride with magnesium chloride in

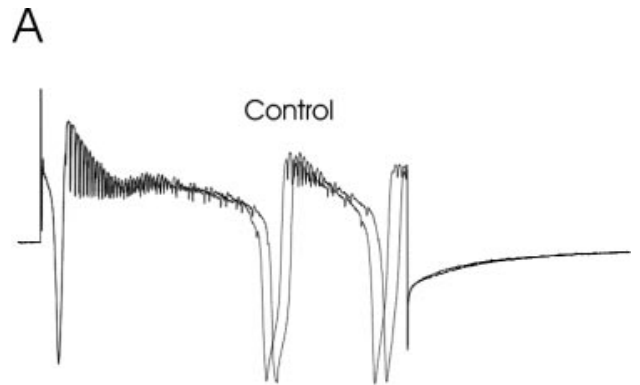

B
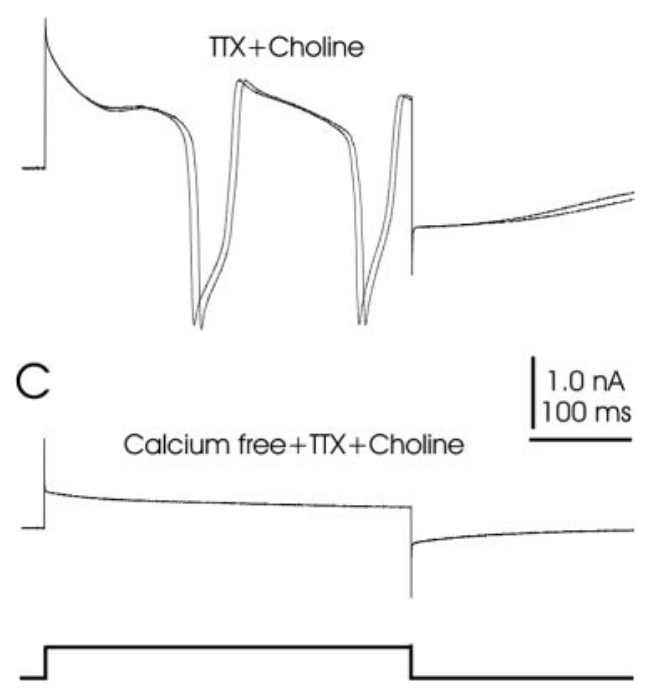

Figure 7. Effects of calcium-free ACSF on late broad spikes in Purkinje cells. All recordings were obtained under voltage clamp. Responses were obtained by voltage steps from -70 to $-25 \mathrm{mV}$. A, Predrug control showing three types of spikes. $B$, Effects of adding TTX $(1 \mu \mathrm{m})$ and replacing sodium chloride with choline chloride. These manipulations result in the disappearance of the small, narrow spikes and the initial broad spike. Late broad spikes are still present and have an increased duration. C, Replacement of calcium with magnesium in the ACSF leads to the disappearance of late broad spikes. Note that the response to a voltage step does not show a hump under these calcium-free conditions.

the ACSF. Use of this calcium-free ACSF resulted in the complete disappearance of the late broad spike (Fig. $7 C$ ), providing further indication that it is a calcium spike. Disappearance of the late broad spike in calcium-free ACSF was observed in six Purkinje cells.

The above results indicate that Purkinje cells in the central lobes of the mormyrid cerebellum have three types of spikes: a small sodium spike, an initial broad sodium spike, and a late broad calcium spike. The small sodium spikes have the lowest threshold to intracellular current pulses, whereas the initial broad sodium spikes have the highest threshold. The threshold for the late calcium spikes is in between these two values. The amplitudes and durations of the two types of broad spikes were surprisingly similar, given that they depend on different ion channels. The durations at half-amplitude for the two types of spikes were measured in the first 13 Purkinje cells recorded with whole-cell patch electrodes in which the internal solution contained cesium. The difference between the duration of the late calcium spike (mean $\pm \mathrm{SD}, 8.2 \pm 1.5 \mathrm{msec}$ ) and the initial sodium spike (9.7 \pm $1.5 \mathrm{msec}$ ) was not significant when the spike durations were measured early in the recording. But the duration of the late spike $(17.9 \pm 5.9 \mathrm{msec})$ became significantly longer $(t$ test; $p<0.001)$ than the duration of the initial spike $(7.8 \pm 1.7 \mathrm{msec})$ after several 
minutes of recording with cesium in the internal solution (compare the two types of spikes in Figs. 6A, 7A). Cesium blocks many potassium channels, and, presumably, these channels have a larger role in the repolarization of the late spike than in the repolarization of the initial spike.

Other voltage-dependent currents

Application of the sodium channel antagonist TTX together with the calcium channel antagonist cadmium did not remove all of the voltage-dependent inward current in mormyrid Purkinje cells. This possibility was suggested by voltage-clamp recordings of responses to depolarizing voltage steps that showed a small hump in the current record after addition of TTX and cadmium (Fig. 5A, $B$, bottom traces). This hump was also observed after addition of TTX and cadmium to ACSF in which the sodium chloride was replaced with choline chloride (Fig. 6D). The small hump was not seen, however, after addition of TTX to ACSF that was calcium-free and in which the sodium chloride was replaced with choline chloride (Fig. $7 C$, bottom trace), suggesting that the hump involves an inward current through a type of calcium channel that was not blocked by $100 \mu \mathrm{M}$ cadmium. Calcium currents that are somewhat resistant to $100 \mu \mathrm{M}$ cadmium have also been described in mammalian Purkinje cells in culture (Gruol et al., 1992).

The voltage-dependent currents that remained after blocking the three types of spikes with TTX and cadmium were investigated more closely by subtracting the passive membrane currents (see Materials and Methods). Depolarizing pulses revealed the presence of both inward and outward currents in the presence of ACSF in which choline chloride was substituted for sodium chloride and to which TTX and cadmium had been added (Fig. $8 \mathrm{~A}$, second trace). The outward current dominated at more depolarized voltage levels (Fig. $8 \mathrm{~A}$, third trace). The outward currents were reduced by the addition of TEA, 4-AP, and barium, which block potassium channels. All of the outward current was not removed by these procedures, but a sufficient amount was removed to reveal more of the time course of the inward current (Fig. $8 \mathrm{~B}$, top trace). This inward current was not present when normal ACSF was replaced with calcium-free ACSF in which choline was substituted for sodium and to which TTX as well as the potassium channel blockers had been added (Fig. 8C,D). Similar results were obtained in 7 Purkinje cells. Taken together, these results suggest the presence of a calcium current in mormyrid Purkinje cells that is not blocked by $100 \mu \mathrm{M}$ cadmium. No further effort was made to identify the calcium or potassium currents in mormyrid Purkinje cells.

\section{Efferent cells, Golgi cells, and stellate cells}

Efferent cells

We recorded from 21 morphologically identified efferent cells. The efferent cells showed only a single type of spike, a large, narrow spike with a prominent afterhyperpolarization, similar to the spikes in many other CNS neurons (Fig. 9A). The responses of efferent cells to current injection were therefore quite distinct from those of Purkinje cells, all of which showed the three types of spikes described in preceding sections. The efferent cells fired repetitively to intracellular current injection with little if any adaptation in rate (Fig. 9A,B). Parallel fiber stimulation evoked EPSCs or EPSPs that showed clear paired pulse facilitation (Fig. 9C). We were not able to evoke large all-or-none EPSPs in efferent cells by stimulation in the ganglionic or granule layer, suggesting that the efferent cells do not receive a prominent climbing fiber input like that received by Purkinje cells. Such stimulation

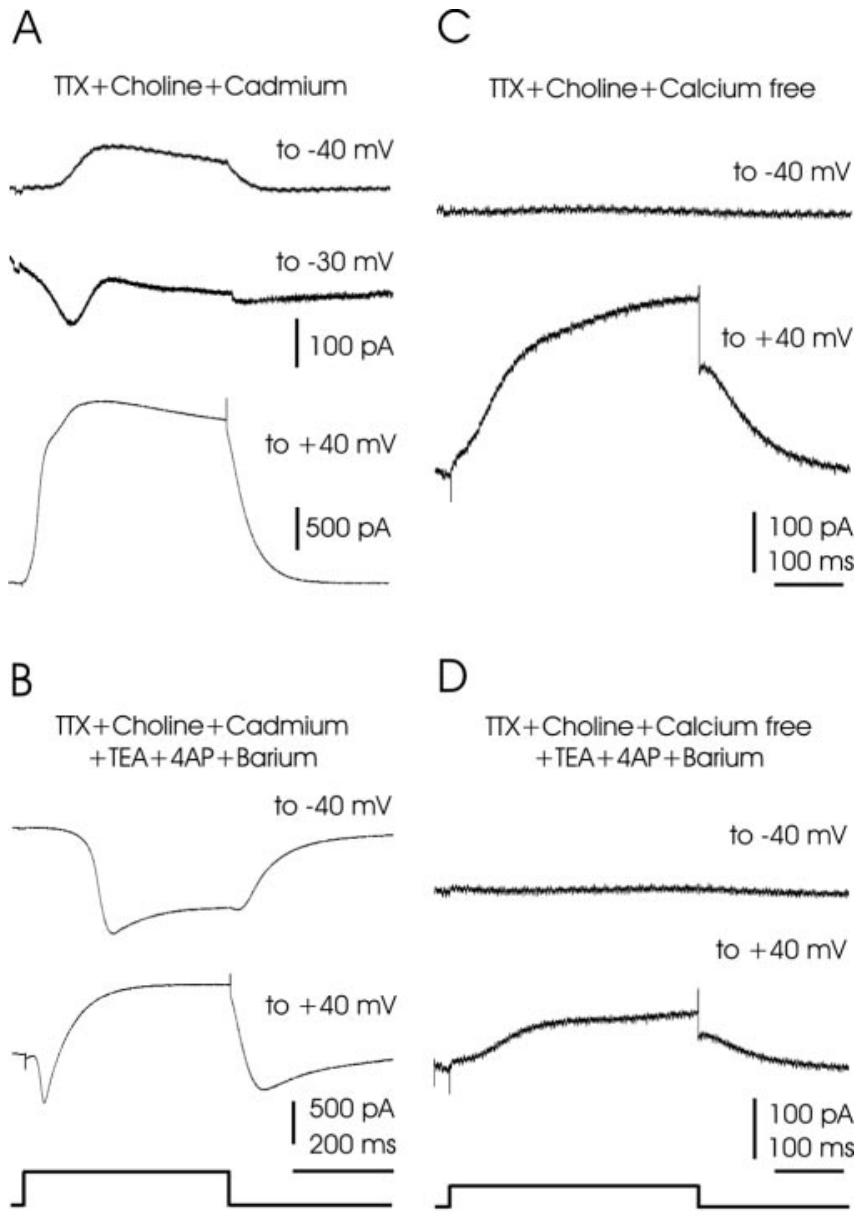

Figure 8. Other voltage-dependent currents in Purkinje cells besides those responsible for the three types of spikes. All recordings were obtained under voltage clamp. Responses were obtained by steps from a holding potential of $-70 \mathrm{mV}$ to the indicated transmembrane potentials. Passive currents were subtracted in each record. $A$, Inward and outward currents in the presence of choline-substituted ACSF with added TTX (1 $\mu \mathrm{M})$ and cadmium (100 $\mu \mathrm{M})$. A depolarization to $-40 \mathrm{mV}$ evoked an outward current (top trace). A larger depolarization to $-30 \mathrm{mV}$ evoked an initial inward current followed by an outward current (middle trace). Only the outward current could be observed with still larger depolarization to $+40 \mathrm{mV}$ (bottom trace). $B$, The TTX $(1 \mu \mathrm{M})$ - and cadmium-insensitive inward current becomes more apparent after partial blockade of potassium channels with TEA $(8 \mathrm{~mm}), 4-\mathrm{AP}(5 \mathrm{~mm})$, and barium $(2 \mathrm{~mm})$. The same cell as in $A$ is shown. A long-lasting inward current can now be observed with depolarizations to $-40 \mathrm{mV}$, and some inward current is still present with depolarizations to $+40 \mathrm{mV}$. C, D, The TTX $(1 \mu \mathrm{M})$ - and cadmium-insensitive inward current is not present in calcium-free ACSF. A different cell from the cell in $A$ and $B$ is shown. No inward current is present even when potassium channels are partially blocked with 4-AP (5 mM), TEA $(8 \mathrm{~mm})$, and barium $(2 \mathrm{~mm})$, as in D.

did sometimes evoke graded EPSPs, but we could not be sure whether these EPSPs were attributable to activation of granule cells, mossy fibers, or climbing fibers.

\section{Golgi cells}

We recorded from four morphologically identified Golgi cells with sharp electrodes. All four cells showed only a single type of spike, a large, narrow spike with a prominent afterhyperpolarization (Fig. 10A). The Golgi cells fired repetitively to intracellular current injection (Fig. 10B). Stimulation in the molecular layer usually evoked a mixed postsynaptic response of EPSPs and IPSPs (Fig. 10A).

Stellate cells

We recorded from three morphologically identified stellate cells, one with sharp electrodes and two with patch electrodes. Stellate 
A
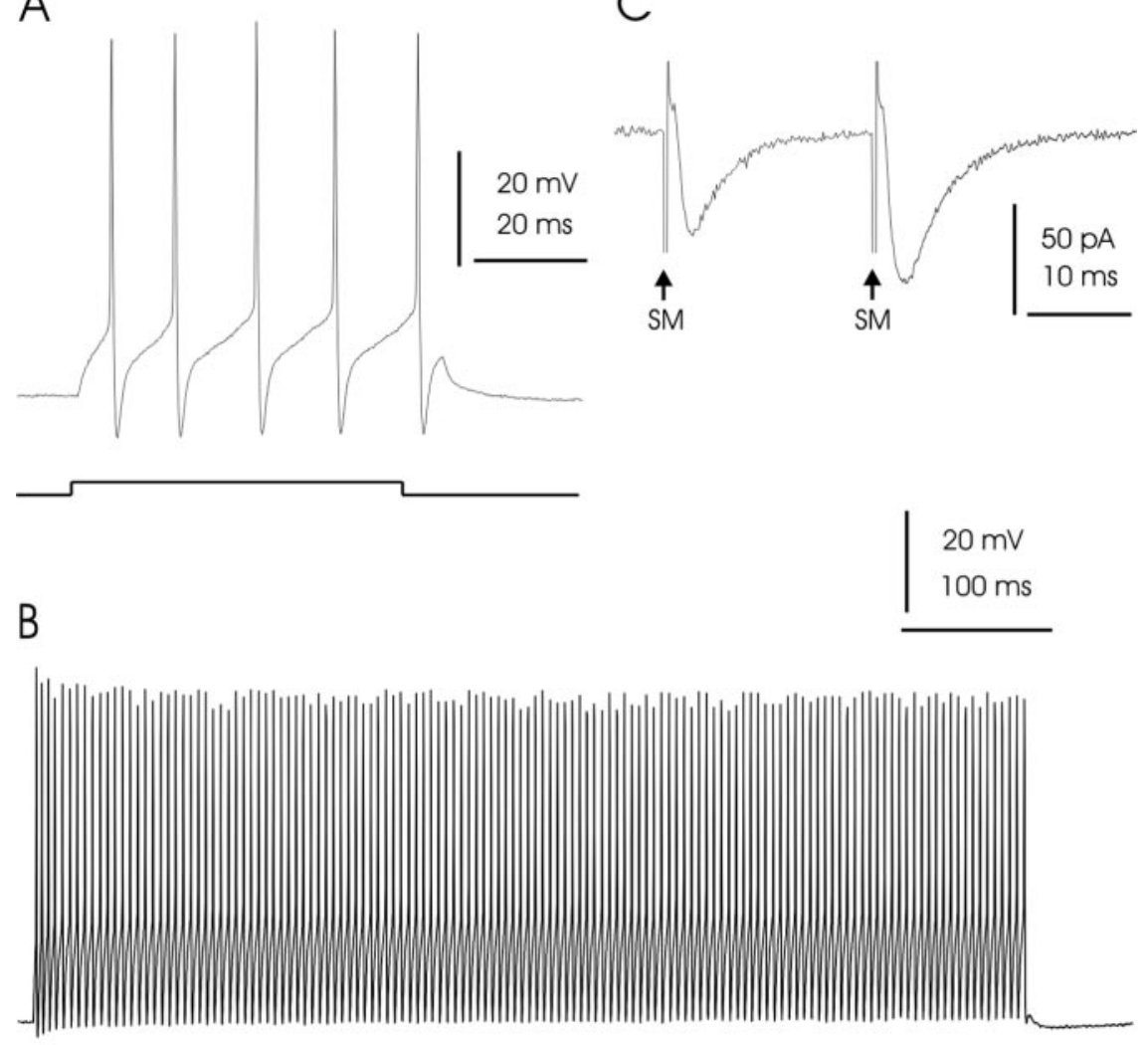

5

Figure 9. Physiological responses of a morphologically identified efferent cell. $A, B$, Intracellular current injection evokes only large, narrow spikes. Recordings were obtained under current clamp. The spike response shows little if any adaptation during the course of the current injection. Currents were 150 and $350 \mathrm{pA}$ in $A$ and $B$, respectively. C, Parallel fiber-evoked EPSC in an efferent cell shows paired pulse facilitation. Recordings were obtained under voltage clamp.

cells also showed only large, narrow spikes with a prominent afterhyperpolarization and responded to current steps with a nonadapting repetitive discharge (Fig. 11A). Stimulation in the molecular layer evoked either an EPSP or an antidromic spike and an EPSP (Fig. $11 B$ ), the EPSP being attributable to parallel fiber activation.

\section{Discussion}

The histological structure of the mormyrid cerebellum is similar in many respects to that of the mammalian cerebellum, and the present study shows that there are also many physiological similarities. These similarities include the following: parallel fibers that conduct at $\sim 0.1 \mathrm{~m} / \mathrm{sec}$ (Eccles et al., 1967); parallel fiber excitation of Purkinje, Golgi, and Stellate cells (Eccles et al., 1967); parallel fiber excitation of Purkinje cells by glutamate receptors of the AMPA type only (Konnerth et al., 1990); generation of large all-or-none EPSPs in Purkinje cells by climbing fibers (Eccles et al., 1967); innervation of single Purkinje cells by single climbing fibers (Eccles et al., 1967); climbing fiber excitation of Purkinje cells by glutamate receptors of the AMPA type only (Konnerth et al., 1990); and the presence of narrow sodium spikes and broad calcium spikes in Purkinje cells (Llinas and Sugimori, 1980b). Some differences between the physiology of mormyrid and mammalian cerebellums were also apparent, however.

The waveform of the climbing fiber responses in Purkinje cells, as recorded under current clamp, was clearly different in the mormyrid and mammalian cerebellums. The waveform in mormyrids consists of two phases, a large brief depolarization lasting $\sim 10$ msec followed by a slow, ramp-like return to the baseline that lasted $\sim 100 \mathrm{msec}$. In contrast, the climbing fiber response in mammals, as recorded in the soma, consists of a long-lasting monophasic potential, which may be in part an EPSP and in part a voltage response of the cell (Eccles et al., 1967; Callaway et al., 1995; Schmolesky et al., 2003). A series of variable spike-like events are usually superimposed on the monophasic potential. Climbing fiber-evoked EPSCs recorded in voltage clamp are rather similar in mormyrids and mammals, however, consisting of a sharply rising inward current followed by an approximately exponential decay.

The differences in climbing fiber responses recorded in current clamp probably reflect the marked differences in how the climbing fiber terminates on Purkinje cells in the two groups. In mormyrids, the climbing fiber does not enter the molecular layer but terminates on the soma and smooth dendrites close to the soma, whereas in mammals, the climbing fiber terminates on smooth dendrites throughout the molecular layer. It is suggested that the large synaptic current into the soma and proximal dendrites results in the passive charging of all the dendritic membrane in the molecular layer that is not reached by the climbing fiber. It is possible that the charge on molecular layer dendrites in the mammal is discharged immediately through the synaptic and voltage-gated conductance changes caused by the climbing fiber.

Another physiological difference between the mormyrid and mammalian Purkinje cells concerns the types of spikes in the two groups. Mormyrid Purkinje cells have a narrow sodium spike, a broad sodium spike, and a broad calcium spike, whereas mammals (Llinas and Sugimori, 1980a) and reptiles (Hounsgaard and Midtgaard, 1988) are generally described as having only a narrow sodium spike and a broad calcium spike. Moreover, in recordings from the soma of mormyrids, the narrow sodium spike is always small, $10-15 \mathrm{mV}$ in amplitude, and the two types of broad spikes are large, $50-70 \mathrm{mV}$. In recordings from the soma of mammalian and reptilian Purkinje cells, however, the narrow sodium spikes are large, and the broad calcium spikes are relatively small.

The small, narrow sodium spike in mormyrid Purkinje cells is thought to be an axon spike that does not invade the soma. In contrast, the large, narrow sodium spike in mammalian Purkinje cells, although initiated in the axon, propagates into the soma (Stuart and Hausser, 1994). This difference may reflect a difference in morphology. The mormyrid axon is thin and unmyelinated and arises abruptly from the soma without an axon hillock (Nieuwenhuys and Nicholson, 1969b; Meek and Nieuwenhuys, 1991), whereas the mammalian axon is thick and myelinated and arises from an axon hillock (Fox, 1962). These differences would be expected to result in different safety factors for the propaga- 

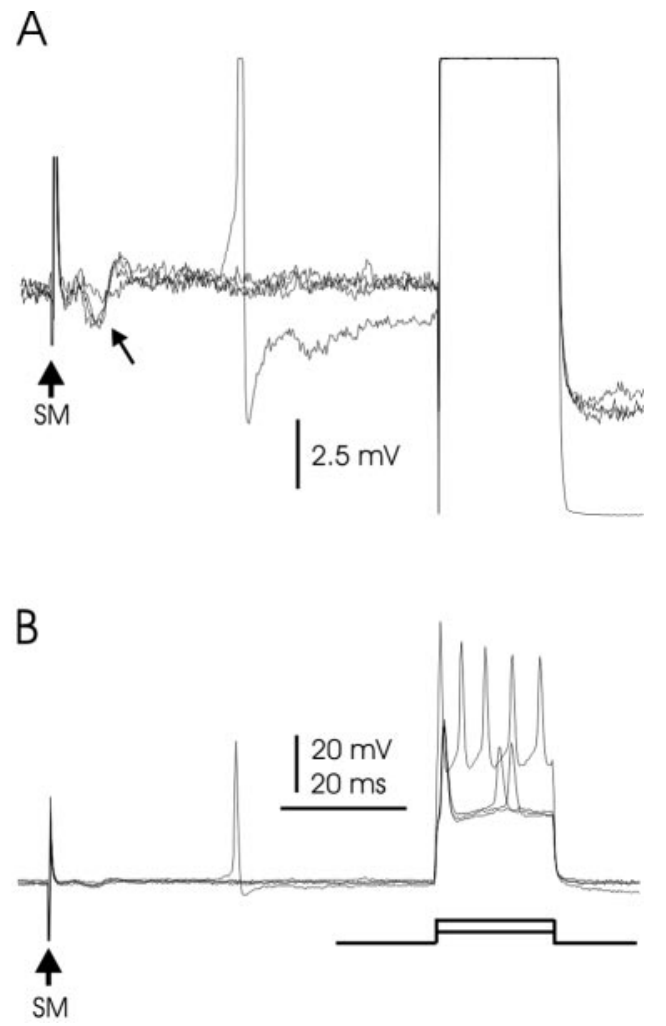

Figure 10. Physiological responses of a morphologically identified Golgi cell. Recordings were obtained under current clamp. A, A molecular layer stimulus evokes a brief IPSP-EPSP sequence. A narrow spike with a biphasic afterhyperpolarization was also evoked. $B$, Same recordings as in $A$ but at a lower gain to show spikes. Sweeps with two levels of current injection ( 250 and $450 \mathrm{pA}$ ) are shown at the right. Repetitive spike firing is evoked by the more intense current.

tion of spikes from axon to soma. However, the fact that we could not evoke large, narrow sodium spikes at all with somatic current injection suggests that there may be fewer sodium channels in the somas of mormyrid Purkinje cells. Purkinje-like cells in the electrosensory lobe of mormyrid fish are similar morphologically to mormyrid Purkinje cells and also have small, narrow sodium spikes that are believed to be axon spikes (Grant et al., 1998).

The broad calcium spikes in mammalian (Llinas and Sugimori, 1980b) and reptilian (Hounsgaard and Midtgaard, 1988) Purkinje cells are rather clearly generated in the dendrites, where they are quite large. The smaller size of these spikes in somatic recordings in mammals is attributable to electrotonic filtering and a lack of active propagation into the soma. The large size of the two types of broad spikes in somatic recordings from mormyrid Purkinje cells suggests that these spikes are generated either in the soma itself or in large dendrites that are electrotonically close to the soma.

The broad sodium spike that we recorded in mormyrid Purkinje cells was not expected because such broad sodium spikes have not been described in most intracellular studies of mammalian Purkinje cells. One study of mammalian Purkinje cells has, however, described a broad, spike-like, regenerative event that is associated with an influx of sodium into the soma (Callaway et al., 1995). In addition, immunocytochemistry shows that mormyrid Purkinje cells have the same types of sodium channels as mammalian Purkinje cells and that the distributions of these channels in the dendrites and somas of the two groups are also similar (M. M. de Ruiter, C. I. de Zeeuw, and C. Hansel, unpublished
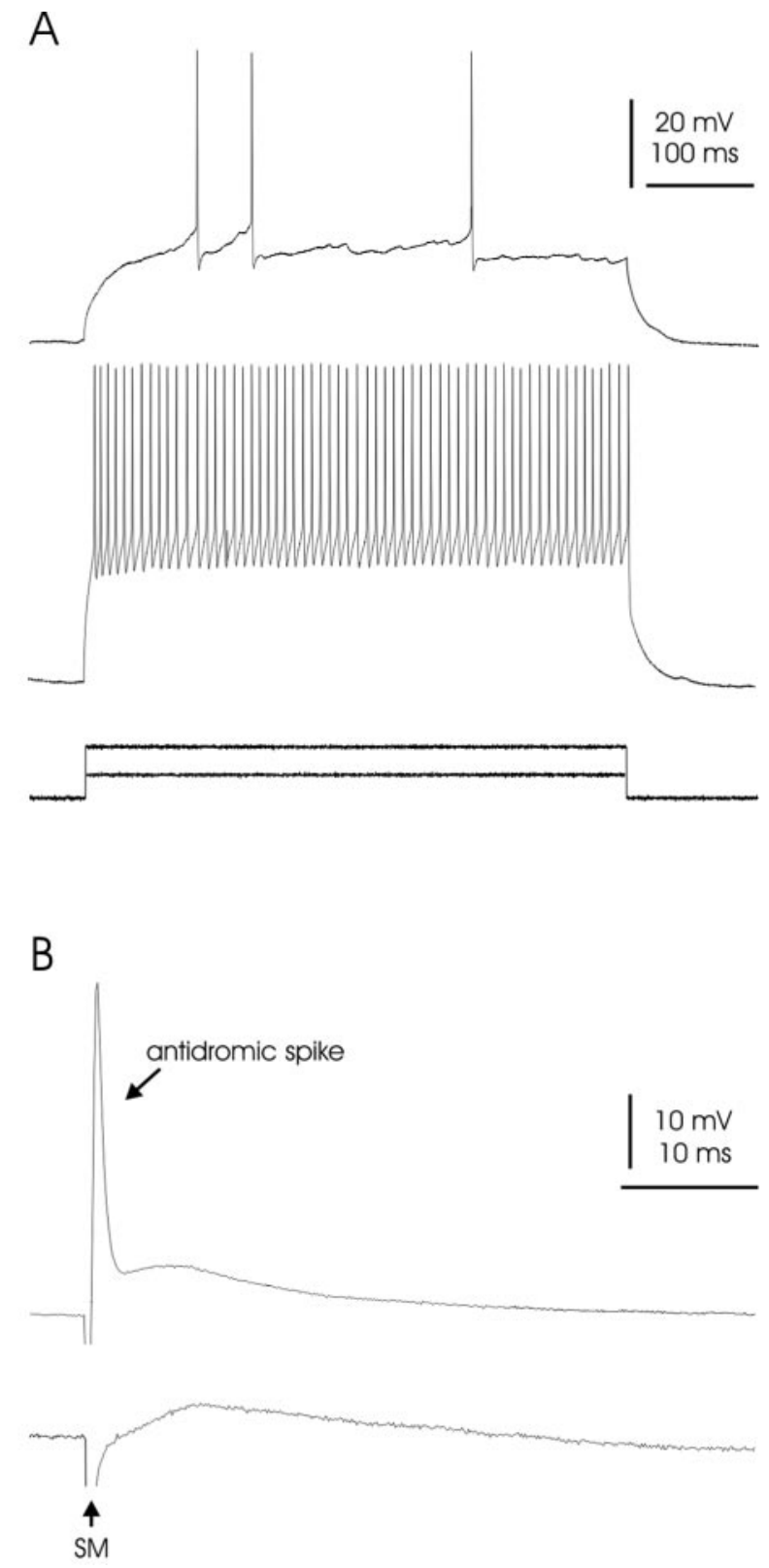

Figure 11. Physiological responses from a morphologically identified stellate cell. Recordings were obtained under current clamp. $A$, Responses to different intensities of injected current. Currents of $250 \mathrm{pA}$ (top trace) and $500 \mathrm{pA}$ (middle trace) were injected into the cell. The injected currents evoke a large, narrow spike with a biphasic afterhyperpolarization. Note the lack of adaptation in response to the more intense current. $B$, A molecular layer stimulus evokes an antidromic spike and an EPSP on one sweep (top trace) and an EPSP alone on another sweep (bottom trace).

results). Thus, a broad sodium spike, like the one in mormyrids, may also occur in mammalian Purkinje cells under some circumstances.

Broad sodium spikes are also present in the Purkinje-like medium ganglion cells of the mormyrid electrosensory lobe (Bell et al., 1997). These sodium spikes are present in recordings from molecular layer dendrites of medium ganglion cells (Mohr et al., 2003), indicating that they propagate into the dendrites of these cells. We have not yet recorded from molecular layer dendrites of mormyrid Purkinje cells. Such recordings, in combination perhaps with imaging studies, will be necessary to determine the cellular loci of both the broad sodium and the broad calcium spikes in mormyrid Purkinje cells. 
Perhaps the most striking difference between the mormyrid and mammalian cerebellums is the pathway by which afferent input affects cerebellar efferent cells. The cerebellar efferent cells in mormyrids are in the cortex close to the Purkinje cells that inhibit them, whereas in mammals, they are in a separate deep cerebellar nucleus. Afferent input to the cerebellum excites efferent cells as well as Purkinje cells in both mormyrids and mammals but does so via different pathways. In mammals, afferent input conveyed by climbing fibers and mossy fibers excites the nuclear cells via collaterals to the deep cerebellar nuclei (Eccles et al., 1967; Ito, 1984) and then excites Purkinje cells. Climbing fibers excite the Purkinje cells monosynaptically, and mossy fibers excite the Purkinje cells disynaptically via granule cells. In mormyrids, the mossy fibers do not contact efferent cells directly but do so indirectly via their synapses on granule cells, the axons of which form parallel fibers that terminate on both efferent cells and Purkinje cells. Our recordings suggested that individual climbing fibers do not evoke large all-or-none EPSPs in efferent cells, but they may have smaller synaptic effects that we could not distinguish in our recordings. We did show that parallel fibers excite efferent cells in a manner that is similar to their excitation of Purkinje cells, indicating that mossy fibers have strong effects on mormyrid efferent cells via the parallel fibers.

The mormyrid pattern of mossy fiber excitation of efferent cells via granule cells and parallel fibers rather than via collaterals of the mossy fibers themselves is common to all ray-finned fishes (Meek, 1998). The cerebellum is prominent in ray-finned fishes and is, of course, particularly prominent in mormyrids. This prominence suggests that the essential functions of the cerebellum are executed quite well by the cerebellar circuitry of rayfinned fishes. The difference between direct excitation of efferent cells by mossy fibers and indirect excitation via granule cells does not seem, therefore, to be a critical difference with regard to the general functions of cerebellar circuitry.

In summary, the present physiological study and morphological work by ourselves (Han, Campbell, and Bell, unpublished results) and others (Nieuwenhuys and Nicholson, 1969a,b; Meek and Nieuwenhuys, 1991) show that the mormyrid cerebellum has many similarities as well as many differences from the cerebellums of mammals. Some of the differences or unique features of the mormyrid cerebellum make it suitable for investigating some aspects of cerebellar function. The similarities to the mammalian cerebellum suggest that what is learned in the mormyrid may be a source of hypotheses regarding cerebellar function in mammals.

\section{References}

Aghajanian GK, Rasmussen K (1989) Intracellular studies in the facial nucleus illustrating a simple new method for obtaining viable motoneurons in adult rat brain slices. Synapse 3:331-338.

Bell CC, Han VZ, Sugawara S, Grant K (1997) Synaptic plasticity in a cerebellum-like structure depends on temporal order. Nature 387:278-281.

Callaway JC, Lasser-Ross N, Ross WN (1995) IPSPs strongly inhibit climbing fiber-activated $\left[\mathrm{Ca}^{2+}\right]_{\mathrm{i}}$ increases in the dendrites of cerebellar Purkinje neurons. J Neurosci 15:2777-2787.

Eccles J, Ito M, Szentagothai J (1967) The cerebellum as a neuronal machine. Berlin: Springer.

Fox CA (1962) The structure of the cerebellar cortex. In: Correlative anatomy of the nervous system (Crosby EC, Humphrey TH, Lauer EW, eds), pp 193-198. New York: Macmillan.

Grant K, Sugawara S, Gomez L, Han VZ, Bell CC (1998) The mormyrid electrosensory lobe in vitro: physiology and pharmacology of cells and circuits. J Neurosci 18:6009-6025.

Gruol DL, Deal CR, Yool AJ (1992) Developmental changes in calcium conductance contribute to the physiological maturation of cerebellar Purkinje neurons in culture. J Neurosci 12:2838-2848.

Han VZ, Bell CC, Grant G, Sugawara Y (1999) In vitro studies of the mormyrid electrosensory lobe: I. Morphology of cells and circuits. J Comp Neurol 404:359-374.

Hashimoto K, Kano M (1998) Presynaptic origin of paired-pulse depression at climbing fibre-Purkinje cell synapses in the rat cerebellum. J Physiol (Lond) 506:391-405.

Hounsgaard J, Midtgaard J (1988) Intrinsic determinants of firing pattern in Purkinje cells of the turtle cerebellum in vitro. J Physiol (Lond) 402:731-749.

Ito M (1984) The cerebellum and neural control. New York: Raven.

Konnerth A, Llano I, Armstrong CM (1990) Synaptic currents in cerebellar Purkinje cells. Proc Natl Acad Sci USA 87:2662-2665.

Llinas R, Sugimori M (1980a) Electrophysiological properties of in vitro Purkinje cell somata in mammalian cerebellar slices. J Physiol (Lond) 305:171-195.

Llinas R, Sugimori M (1980b) Electrophysiological properties of in vitro Purkinje cell dendrites in mammalian cerebellar slices. J Physiol (Lond) 305:197-213.

Meek J (1998) Holosteans and teleosts. In: The central nervous system of vertebrates (Nieuwenhuys R, Ten Donkelaar HJ, Nicholson C, eds), pp 759-937. Berlin: Springer.

Meek J, Nieuwenhuys R (1991) Palisade pattern of mormyrid Purkinje cells: a correlated light and electron microscopic study. J Comp Neurol 306:156-192.

Mohr C, Roberts PD, Bell CC (2003) Cells of the mormyromast region of the mormyrid electrosensory lobe: I. Responses to the electric organ corollary discharge and to electrosensory stimuli. J Neurophysiol 90:1193-1210.

Nieuwenhuys R, Nicholson C (1969a) A survey of the general morphology, the fiber connections, and the possible functional significance of the gigantocerebellum of mormyrid fishes. In: Neurobiology of cerebellar evolution and development (Llinas R, ed), pp 107-134. Chicago: American Medical Association.

Nieuwenhuys R, Nicholson C (1969b) Aspects of the histology of mormyrid fishes. In: Neurobiology of cerebellar evolution and development (Llinas R, ed), pp 135-169. Chicago: American Medical Association.

Schmolesky MT, Weber JT, de Zeeuw CI, Hansel C (2003) The making of a complex spike: ionic composition and plasticity. Ann NY Acad Sci 978:359-390.

Stuart G, Hausser M (1994) Initiation and spread of sodium action potentials in cerebellar Purkinje cells. J Neurosci 13:703-712. 